\title{
Genotype C/C 13910 of the Lactase Gene as a Risk Factor for the Formation of Insulin-Resistant Obesity in Children
}

\author{
Aleksandr Abaturov, Anna Nikulina*
}

\begin{abstract}
Introduction: To reduce the risk of insulin resistance in obesity in children with lactase gene genotypes, we studied the factors that stimulate the chronic inflammatory process. Material and methods: 109 children 6-18 years of age were investigated. The main group $(n=56)$ was presented by children with signs of insulin-resistant obesity according to the criteria of the European Society of Endocrinology and the Pediatric Endocrine Society. The control group $(n=53)$ included obese children without insulin resistance. A comprehensive clinical examination, food diary analysis, genotyping of the lactase gene by means of the polymerase chain reaction, the Immunochemical Test Method with Electrochemiluminescent Detection of basal insulinemia, Hydrogen breath test with lactose load, sequential analysis, ROC analysis were carried out. Results: Clinical manifestations of lactose maldigestion in a child increased the risk of possible insulin resistance (prognostic coefficient $(P C+2.6)$, as well as the presence of the lactase $C / C 13910$ gene genotype $(P C+5.8)$ did. The genotype $C / T 13910$ in children had a protective effect on the risk of obesity (PC -2.9). The lowest risk of insulin-resistant obesity in observed among children with the genotype T/T 13910 (PC -12). Conclusion: The presence of the C/C 13910 genotype of the lactase gene is the main factor formation of insulin resistance in children's obesity.

What is known? The genotype C/C 13910 of the lactase gene as a risk factor for the chronic inflammatory process in the body.

What is New? Genotype C/C 13910 of the lactase gene as a risk factor for insulin-resistant obesity in children.
\end{abstract}

KEYWORDS

genotype C/C 13910; children; lactose maldigestion; obesity; insulin resistance

\section{AUTHOR AFFILIATIONS}

Department of Pediatrics and Medical Genetics, State Institution "Dnepropetrovsk Medical Academy of the Ministry of Health of Ukraine", Dnipro, Ukraine

* Corresponding author: State Institution "Dnepropetrovsk Medical Academy of the Ministry of Health of Ukraine", Street 9, V. Vernadskogo, 49044, Dnipro, Ukraine; e-mail: anna.nikulina.201381@gmail.com

Acta Medica (Hradec Králové) 2019; 62(4): 150-155

https://doi.org/10.14712/18059694.2020.4

(c) 2019 The Authors. This is an open-access article distributed under the terms of the Creative Commons Attribution License (http://creativecommons.org/licenses/by/4.0), which permits unrestricted use, distribution, and reproduction in any medium, provided the original author and source are credited. 


\section{INTRODUCTION}

The discrepancy between the amount of lactose being consumed in the diet and the ability to secrete the lactase enzyme underlies the persistence of the chronic inflammatory process and the formation of obesity and insulin resistance. The degree of transcription of the lactase gene (LCT), OMIM 603202NG_008104 depends on the characteristics of the MCM6 (minichromosome maintenance complex 6) enhancer. Single nucleotide polymorphisms (SNP) of the cis-regulatory element MCM6, which are characterized by the replacement of cytosine (C) with thymine (T) in the 13th MCM6 intron at position 13910 for $14 \mathrm{~kb}$ from the LCT locus, cause a high penetrance of the lactase gene. The average level of lactase activity in European children with the genotype C/C 13910 is $6.5 \mathrm{U} / \mathrm{g}$ (adult-type lactase deficiency, $\mathrm{LD}$ ), while the activity of lactase with the $\mathrm{C} / \mathrm{T}$ genotype is $29.9 \mathrm{U} / \mathrm{g}$ (heterozygous lactase persistence), and with genotype T/T $50 \mathrm{U} / \mathrm{g}$ (homozygous lactase persistence) (1).

Our study focuses on solving one of the global medical and social problems in pediatrics caused by a significant spread of childhood obesity in an urbanized society (2) with LCT genotypes, studying the factors that cause chronic inflammation.

The aim of this work was to study the factors that induce insulin resistance within obesity in children caused by a genetically determined impairment of lactose digestion.

\section{MATERIALS AND METHODS}

To build a mathematical model for predicting the probability of insulin-resistant obesity in the early diagnostic stage, out of 109 children aged 6-18 years, two groups were identified. The main group $(n=56)$ was presented by children with insulin-resistant obesity according to the recommendations of The European Society of Endocrinology and the Pediatric Endocrine Society (3). The control group $(\mathrm{n}=53)$ was formed by children with no signs of insulin-resistant obesity.

Genotyping was carried out at the polymorphic locus of the LCT gene by real-time polymerase chain reaction (RT-PCR) in 109 obese children from 6 to 18 years of age in a certified laboratory Synevo. The material for the study was venous blood.

Genotyping for signs of allelic polymorphism of the c.-13910 T>C LCT gene was started on the extraction of genomic DNA from peripheral blood leukocytes using the AmliPrime DNA-Sorb B reagent kit according to the manufacturer's instructions (CFX96 (BioRad), USA). In order to recognize alleles in the studied samples, the following classification was used: Allele 1 - allele, the indicated position of the $\mathrm{C} \rightarrow$ T replacement; Allele 2 is the allele indicated after the $\mathrm{C} \rightarrow \mathrm{T}$ replacement position. Amplifications were performed on a CFX 96 amplifier (BioRad, USA) with the addition of up to $20 \mathrm{ng}$ of isolated reaction mixture containing: $20 \mu \mathrm{g}$ of SNP Genotyping Assay Mix (Applied Biosystems, USA) and 2 ng of Universal PCR Master Mix buffer solution (Applied Biosystems, USA). In the process of amplification, a simultaneous hybridization - fluorescence detection was performed on samples using fluorescent probes on a DNA analyzer according to the Assays-onDemand protocols for SNP genotyping (No 4331183, Applied Biosystems, USA). Thus, three types of amplification products were determined: determination of the fluorescent signal only from the VIC dye - homozygote for gene 1 (genotype C/C 13910), simultaneously fluorescent signals from the dye VIC and FAM - heterozygote for genome 2 (genotype C/T 13910), fluorescent signal only from FAM dye - homozygote for genome 2 (T/T 13910 genotype).

To detect basal insulinemia and glycaemia in venous blood, the Immunochemical Test Method with Electrochemiluminescent Detection (ECLIA) in the Synevo laboratory was used. We calculated the level of sensitivity of peripheral tissues to insulin, the insulin resistance index HOMA (Homeostasis Model Assesment), using the formula (1):

HOMA-IR $=($ fasting glycaemia $(\mathrm{mmol} / \mathrm{L}) \times$ fasting insulin $(\mu \mathrm{AU} / \mathrm{L})) / 22.5(1)$.

HOMA-IR is one of the clinical criteria for insulin resistance. An increase in insulin resistance was observed with HOMA-IR> 95th percentile, respectively, with percentile curves recommended by the IDEFICS Consortium for the European population according to the age and gender of the child (4).

Hydrogen breath test with lactose load, $25 \mathrm{~g}$ (HBTLL). The concentration of hydrogen in exhaled air was determined by the Gastro + Gastrolyser gas analyzer of the British company Bedfont ${ }^{\circledR}$ Scientific Ltd in parts per million (ppm) with an accuracy of $\pm 1 \mathrm{ppm}$. Automatic data analysis was performed using GastroCHART software (Bedfont ${ }^{\circledR}$ Scientific Ltd Station Road, Harrietsham, Maidstone, Kent, ME17 1JA, UK). Duration HBTLL was 3 hours at intervals of 30 minutes. A test was considered positive when the level of hydrogen in exhaled air increased after 60 minutes, by more than $20 \mathrm{ppm}$ compared to the basal level and clinical symptoms of lactase intolerance (abdominal pain, flatulence, and diarrhea) appeared on a visual-analogue scale for the next eight hours observations (5).

In determining the gradation of quantitative variables, generally accepted ideas about the risk factors of obesity complicated with insulin resistance were used (3, 6-8).

The algorithm for constructing a prognostic model included the following steps (9):

- Calculation of weighted prognostic (diagnostic) coefficients (PC) for each factor using the sequential analysis of Wald and determining the Kullback's informative coefficient (I) for each factor;

- Selection of factors with sufficient informativeness $(\mathrm{I} \geq 0.5)$ and the compilation of a prognostic model that included only those signs that had sufficient informativeness;

- Calculation of the total score of prognostic factors $(\Sigma \mathrm{PC})$ for each observation in the study groups;

- Definition of logistic regression parameters by total points and calculation of the theoretical probability of insulin-resistant obesity for each observation;

- Development of a scale for assessing the probability of insulin-resistant obesity by the total score;

- Evaluation of the developed prognostic model with the use of ROC analysis and other statistical criteria. 
To predict the disease, we carried out a sequential procedure for summing up diagnostic (prognostic) factors. Prognostic factors corresponded to the signs identified in the patient before reaching the diagnostic threshold. The choice of diagnostic thresholds (the sum of diagnostic factors), allowing to predict the occurrence of pathology, was carried out using errors of type 1 and type 2 , and to achieve an accurate prediction probability of $95 \%$ focused on the range: $\Sigma P C \geq 13.0$ - pathology is predicted, or $\Sigma P C \leq$ -13.0 - the absence of pathology is predicted. Accordingly, in order to achieve a $99 \%$ probability of an error-free forecast, we focused on the range of $\Sigma \mathrm{PC} \geq 20.0$ and $\Sigma \mathrm{PC} \leq$ -20.0 , respectively. If the amount was in the range between certain diagnostic thresholds, we concluded that there is not enough information to make a decision about the indicated error levels. The obtained sum of points of prognostic factors $(\Sigma P C)$ for each observation was calculated taking into account the corresponding weight qualification (Fig. 1) and on its basis, the parameters of logistic regression were determined by formulas (2), (3):

$\mathrm{P}=\exp (\mathrm{z}) /(1+\exp (\mathrm{z})), \mathrm{z}=\mathrm{b}_{0}+\mathrm{b}_{1} \times(\Sigma \mathrm{PC})(2)$, where $\mathrm{P}$ is the theoretical probability of insulin-resistant obesity in children; $\Sigma \mathrm{PC}$ is the sum of points for a specific patient; $b_{0}$ and $b_{1}$ are regression coefficients.

The resulting regression equation:

$\mathrm{P}=\exp (1.0976614708555+(0.11163272142568) \times \Sigma \mathrm{PC})$

$/(1+\exp (1.0976614708555+(+0.11163272142568) \times$ $\Sigma \mathrm{PC}))(3)$.

Building a regression equation with the determination of threshold values of the total score allowed us to develop a classification by $\Sigma$ PC to determine children with low, medium and high risk of developing insulin-resistant obesity. The criterion for assigning a child to a particular risk group was the value of the calculated probability $\mathrm{P}$, which ranges from 0 to 1 , and a level greater than 0.5 (or 50\%) indicates an increased risk and corresponds to $\Sigma \mathrm{PC}$ more than 10 points.

Statistical processing of research results included calculation of Spearman's rank correlation coefficient, Wald sequential analysis with the use of the STATISTICA software package (version 6.1) of the AGAR 909E415822FA serial number, adapted for biomedical research. ROC analysis and construction of ROC curves was carried out in the software package of the trial version of Medical Software Software 17.4 (MedCalc Software, Ostend, Belgium, https:// www.medcalc.org, 2017).

\section{RESULTS}

In 56 children with insulin-resistant obesity (main group) and 53 children without insulin-resistant obesity (control group) aged 6-18, the following lactase gene genotypes were determined. The main group was dominated by the C/C 13910 genotype - in $51.76 \%$ of patients (29/56), the C/T 13910 genotype was found in $35.29 \%$ of the patients (20/56), the T/T 13910 genotype - only in $12.94 \%$ of patients (7/56). In children of the control group, the $\mathrm{C} / \mathrm{C}$ 13910 genotype was found in $25 \%(13 / 53)$, the C/T 13910 genotype in $54.17 \%(29 / 53)$, the T/T 13910 genotype in $20.83 \%$ (11/53). By gender, in the main clinical group, boys predominated (60.4\% versus $39.6 \%)$. Then, as among the children of the control group, girls prevailed, the number of which was $58.33 \%$ versus $41.66 \%$ of boys, but the statistical significance of these differences was not observed $(p>0.05)$.

Risk factors for the formation of insulin resistance correlate most strongly among themselves in the group of examined children with the LCT C/C 13910 genotype. In this group of examined patients, the presence of insulin-resistant obesity correlates with the level of systolic blood pressure (SBP) $-\rho=0.48(p<0.05)$, the ratio of the waist circumference to the hips $(\mathrm{WC} / \mathrm{HC})$ is $\rho=0.45(p<0.05)$. HOMA-IR index before treatment is $\rho=0.54(p<0.05)$, which in turn associated with an indicator of a hydrogen respiratory test with lactose load (HBTLL) $>20 \mathrm{ppm}(\rho=$ $0.41 ; p<0.05)$.

Analysis of the clinical and anamnestic characteristics of children who had various forms of obesity allowed us to separate the risk factors for insulin-resistant obesity at an early diagnostic stage.

To determine the specific weight of each of the 243 analyzed clinical and biological factors, the prognostic factor (PC) was calculated. When comparing the age structure of children with insulin-resistant obesity and metabolically favorable obesity, we found that the minimum risk of insulin resistance is possible at the age from 4 to 8 years (PC -4.5), and the maximum risk - at the age from 12 to 18 years $(P C+2.7)$. Gender features did not have a statistically significant effect on the risk of the formation of metabolically unfavorable obesity.

The risk of insulin resistance increases the complicated antenatal period $(\mathrm{PC}+3.6)$; hereditary burden of metabolic syndrome $(\mathrm{PC}+2,9)$; the presence of overweight in early childhood $(\mathrm{PC}+3)$; the presence of pneumonia at puberty $(\mathrm{PC}+7)$; tallness or physical development at the time of the study, above the 67.34th percentile $(\mathrm{PC}+1.8)$; violation of puberty initiation $(\mathrm{PC}+5,8)$; acne vulgaris (PC $+6)$. Studying the eating behavior of children with various forms of obesity based on food diaries has shown that the average duration of food increases the risk of insulin-resistant obesity to less than 10 minutes $(P C+4.5)$. Then, as a quiet meal during 20 minutes reduces the risk of insulin resistance (PC -6.7). Significantly increases the probability of insulin resistance and nutritional composition. For example, daily consumption of red meat, sausages, potatoes, rice, margarine, sugary drinks increases the risk of the formation of insulin-resistant obesity $(\mathrm{PC}+6.4)$. On the contrary, daily consumption of fresh vegetables and fruits in the form of 2-3 portions (children's palms) reduces the risk of insulin resistance (PC -5.5). Lifestyle modification requires reducing non-academic use of a computer/TV or other gadgets to 3 hours per day $(\mathrm{PC}+4.9)$. Clinical manifestations of LD in a patient increased the risk of possible insulin-resistant $(\mathrm{PC}+2.6)$, as did the presence of the lactase $C / C 13910$ gene genotype $(P C+5.8)$. The presence of the genotype C/T 13910 has a protective effect on the risk of obesity (PC -2.9). However, the lowest risk of insulin-resistant obesity was observed in children with the genotype T/T 13910 (PC -12).

The ranking according to the Kullback's (I) informative coefficient showed that the first places among the factors 
that predict insulin-resistant obesity in children at an early diagnostic stage are occupied by the genotype of the lactase gene $(\mathrm{I}=3.49)$, the level of basal insulinemia ( $\mathrm{I}=$ 3.02) and the lack of daily use up to $2-3$ portions of fresh vegetables and fruits $(I=2.71)$, these factors and others have a high informative significance $(3.0>\mathrm{I} \geq 1.0)$.

A moderate informative (diagnostic) significance (1.0 > I $\geq 0.50$ ) was characteristic of the pathological course of pregnancy in the proband mother. Low prognostic information $(0.5>\mathrm{I} \geq 0.20)$ is established for the presence of chickenpox in history, the prevalence of fast food in the diet. These factors have been removed from the prognostic model, table 1 .

Tab. 1 Prediction table for insulin-resistant obesity in children at an early diagnostic stage before the onset of insulin resistance.

\begin{tabular}{|c|c|c|c|}
\hline Prognostic sign & Gradation of the sign & PC & I \\
\hline \multirow{3}{*}{ Lactase gene genotype } & $\mathrm{T} / \mathrm{T} 13910$ & -12.0 & \multirow{3}{*}{3.49} \\
\hline & C/T 13910 & -2.9 & \\
\hline & C/C 13910 & 5.8 & \\
\hline \multirow{2}{*}{$\begin{array}{l}\text { The level of basal } \\
\text { insulinemia, } \mathrm{mklU} / \mathrm{ml}\end{array}$} & $0.88-18.35$ & -0.8 & \multirow{2}{*}{3.02} \\
\hline & $\geq 18.36$ & 9.0 & \\
\hline \multirow{2}{*}{$\begin{array}{l}\text { Daily consumption } \\
\text { of up to } 2-3 \text { portions } \\
\text { of fresh vegetables } \\
\text { and fruits }\end{array}$} & No & 7.6 & \multirow[b]{2}{*}{2.71} \\
\hline & Yes & -5.5 & \\
\hline \multirow{2}{*}{$\begin{array}{l}\text { The presence } \\
\text { of pneumonia } \\
\text { in history }\end{array}$} & No & -5.2 & \multirow{2}{*}{2.51} \\
\hline & Yes & 7.0 & \\
\hline \multirow{3}{*}{$\begin{array}{l}\text { Duration of non- } \\
\text { academic time spent } \\
\text { at a computer/TV }\end{array}$} & $<1$ hour & -6.1 & \multirow{3}{*}{2.42} \\
\hline & $1-2$ houres & 0.1 & \\
\hline & $>3$ houres & 4.9 & \\
\hline
\end{tabular}

\section{PREDICTORS FORMATION} INSULIN RESISTANCE

4

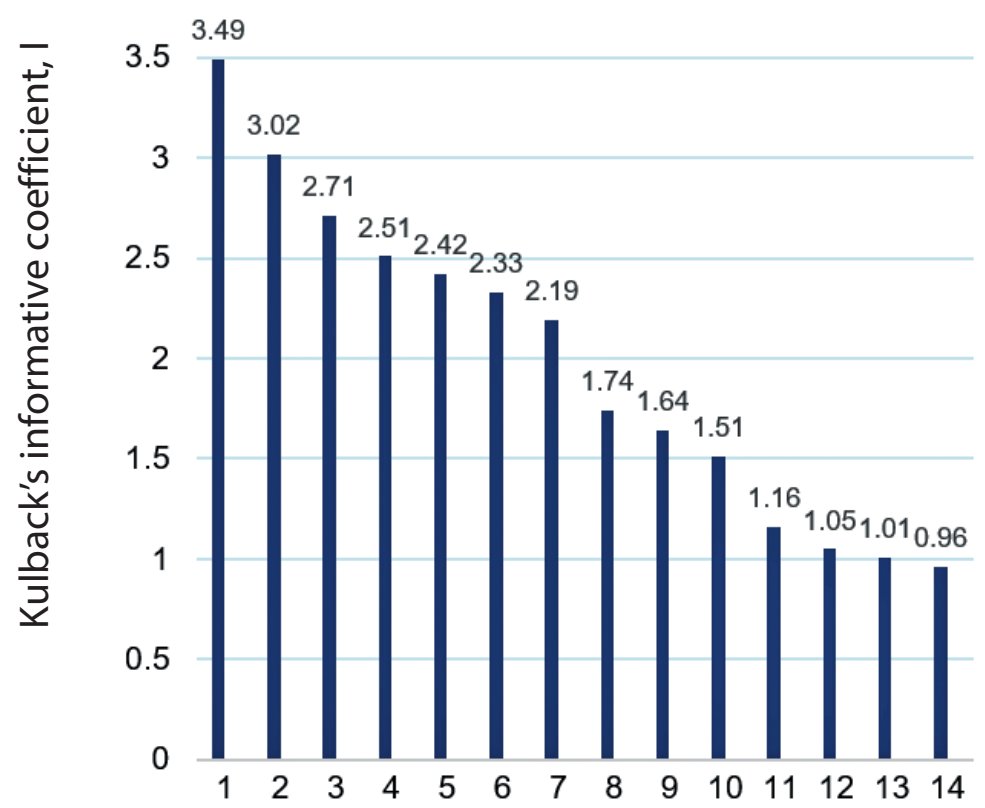

\begin{tabular}{|c|c|c|c|}
\hline \multirow{3}{*}{ Average meal duration } & up to 10 minutes & 4.5 & \multirow{3}{*}{2.33} \\
\hline & 10-20 minutes & 0.6 & \\
\hline & more than 20 minutes & -6.9 & \\
\hline \multirow{2}{*}{$\begin{array}{l}\text { Presence of acne } \\
\text { vulgaris }\end{array}$} & No & -4.8 & \multirow{2}{*}{2.19} \\
\hline & Yes & 6.0 & \\
\hline \multirow{2}{*}{$\begin{array}{l}\text { Daily consumption } \\
\text { of red meat, sausages, } \\
\text { potatoes, rice, } \\
\text { margarine, sugary } \\
\text { drinks }\end{array}$} & No & -1.1 & \multirow[b]{2}{*}{1.74} \\
\hline & Yes & 6.4 & \\
\hline \multirow{2}{*}{$\begin{array}{l}\text { Violation of the age } \\
\text { norms of puberty } \\
\text { initiation }\end{array}$} & No & -3.2 & \multirow{2}{*}{1.64} \\
\hline & Yes & 5.8 & \\
\hline \multirow{3}{*}{$\begin{array}{l}\text { The age of the child } \\
\text { at the time } \\
\text { of inspection }\end{array}$} & $4-8$ years & -4.5 & \multirow{3}{*}{1.51} \\
\hline & $8-12$ years & -5.2 & \\
\hline & $12-17$ years & 2.7 & \\
\hline \multirow{2}{*}{$\begin{array}{l}\text { Hereditary burden } \\
\text { of metabolic syndrome }\end{array}$} & No & 2.4 & \multirow{2}{*}{1.16} \\
\hline & Yes & 2.9 & \\
\hline \multirow{3}{*}{$\begin{array}{l}\text { The level of physical } \\
\text { development } \\
\text { of the child } \\
\text { in percentiles }\end{array}$} & $<33.67$ & -8.0 & \multirow{3}{*}{1.05} \\
\hline & $33.67-67.34$ & -1.2 & \\
\hline & $>67.34$ & 1.8 & \\
\hline \multirow{2}{*}{$\begin{array}{l}\text { Being overweight } \\
\text { at an early age }\end{array}$} & No & -3.4 & \multirow{2}{*}{1.01} \\
\hline & Yes & 3.0 & \\
\hline \multirow{2}{*}{$\begin{array}{l}\text { Pathological course } \\
\text { of pregnancy }\end{array}$} & No & -2.8 & \multirow{2}{*}{0.96} \\
\hline & Yes & 3.6 & \\
\hline
\end{tabular}

Thus, we identified 14 the most prognostically and diagnostically significant clinical and biological predictors of the formation of insulin-resistant obesity in children from 6 to 18 years old, with sufficient informative prognostic significance $(I \geq 0.5)$, figure 1 .

Fig. 1 Predictors of the formation of insulin-resistant obesity in children.

1. The genotype of the gene lactase C/C 13910

2. The level of basal insulinemia more than $18.36 \mathrm{mklU} / \mathrm{ml}$

3. Lack of daily eating of up to $2-3$ portions of fresh vegetables and fruits

4. Postponed pneumonia aged 11-14 years

5. Non-academic use of gadgets for more than 3 hours

6. Duration of food up to 10 minutes

7. Presence of acne vulgaris

8. Daily consumption of red meat, sausages, potatoes, rice, margarine, sugary drinks

9. Violation of puberty initiation

10. Age from 12 to 17 years

11. Hereditary burden of metabolic syndrome

12. The level of physical development of more than 67.34 percentiles

13. Overweight at an early age

14. Pathological maternal pregnancy 


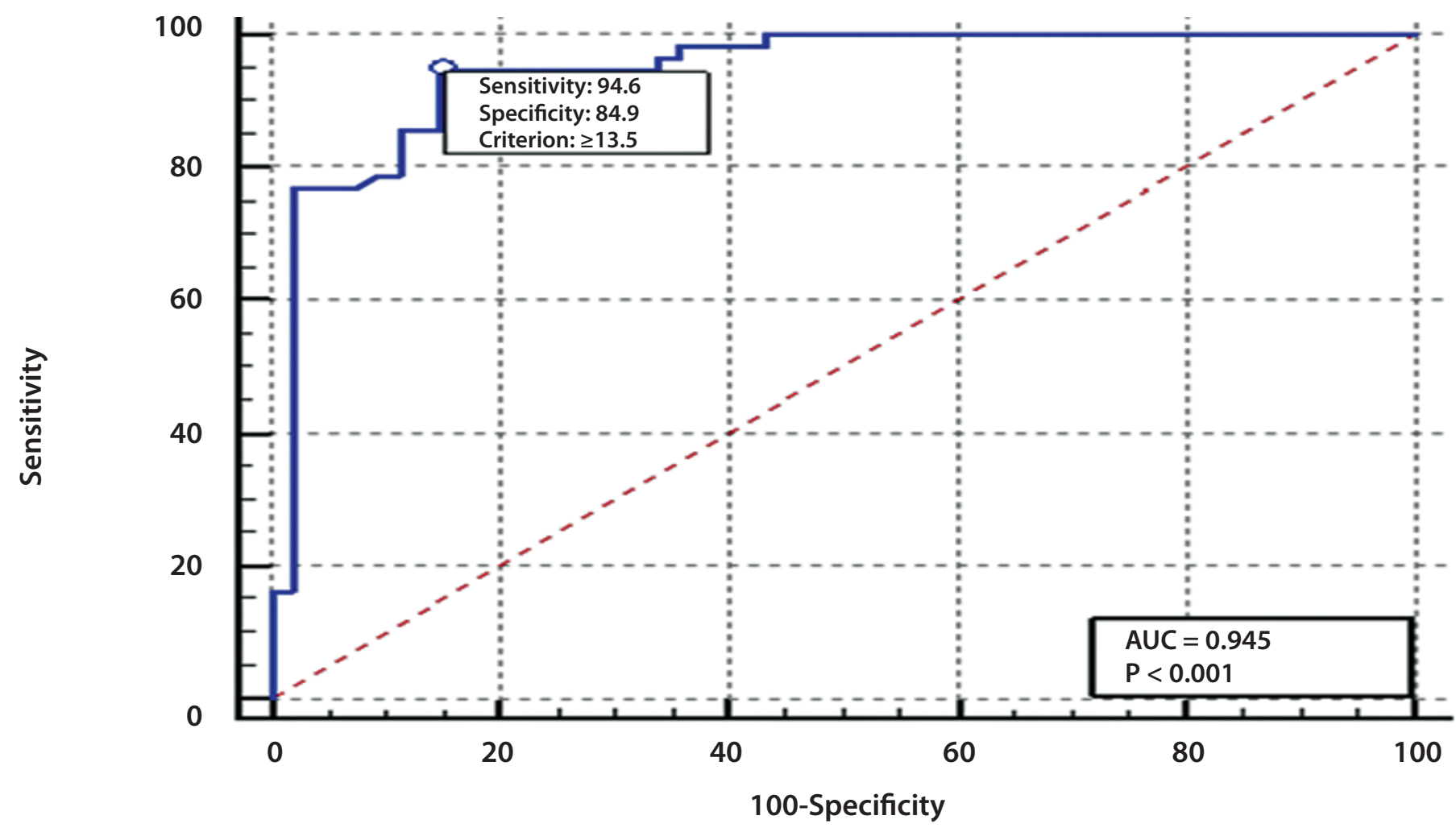

Fig. 2 Operational characteristics of a model for predicting morbid obesity in children at an early diagnostic stage according to ROC analysis.

The developed prognostic model for the development of morbid obesity in children has excellent operational characteristics, figure 2 .

Sensitivity $94.64 \%$, specificity $84.91 \%$ and their generalized indicator is the area under the ROC curve AUC = $0.945(p<0.001)$ with $95 \%$ CI $0.884-0.980$. Test predict a negative result $-83.16 \%$. The proportion of correct prediction of the patient's actual belonging to one group or another (whether it is insulin-resistant obesity or not) was $87.16 \%$, which indicates a high consistency in the actual distribution of observations for the presence of pathological obesity and distribution based on the prognostic model.

\section{DISCUSSION}

The presented model for predicting insulin-resistant obesity in children confirmed the data of previous studies on the importance of lifestyle modification: nutrition and physical activity $(2,3,10)$. Excess lactose in the diet of modern humans causes clinical manifestations of genetically determined lactase deficiency (11). A survey conducted by Lucyna Ostrowska et al. (12) showed that the ability to digest lactose in adult men correlates with low basal hyperinsulinemia. In individuals with the C/C 13910 genotype, reduction of the signaling pathway Gal-9/Tim3 stimulates the synthesis of pro-inflammatory cytokines and forms a metabolically unfavorable insulin-resistant phenotype.

According to our study, the maximum risk of insulin-resistant was observed at the age from 12 to 17 years. The presence of pneumonia, precisely during puberty (13), which is characterized by the presence of physiological in- sulin resistance significantly, worsens the risk of metabolic adverse obesity in children.

The data obtained coincide with the results of studies demonstrating the relationship between inhibition of excess galectin-9/Tim- 3 signaling pathway by excess lactose and the level of invasiveness of pathological factors (14).

Violation of the initiation of sexual development has gender dissociation and is associated with the development of normogonadotropic hypogonadism in boys and the syndrome of isolated adrenarche in girls. At the same time, activation of contrinsular hormones explains accelerated physical development and high height with insulin resistance. Chronic hyperinsulinemia, which is primarily compensatory, to support euglycemia, leads to the activation of lipolysis in visceral adipose tissue with the release of free fatty acids (FFA), which is an important metabolic risk factor for dyslipoproteinemia and leptin-resistance progression. FFA, among which acetate $(60 \%)$, butyrate (15-20\%), propionate $(20-25 \%)$, which also accumulate when excessive use of lactose in the intestinal lumen, interact with the receptor GRP41 enteroendocrine cells of the intestine, causing an increase in the synthesis of the intestinal peptide YY, which slows down the intestinal transit time and reduces the feeling of fullness (7).

Despite the progress achieved in endocrinology and molecular genetics, the problem of childhood obesity remains highly relevant and requires further research on the influence on key metabolic risk factors.

\section{CONCLUSION}

The main risk factors for the development of pathological obesity in the early diagnostic stage are the genotype of 
the lactase $\mathrm{C} / \mathrm{C} 13910$ gene, basal hyperinsulinemia and the lack of daily consumption of up to 2-3 portions of fresh vegetables and fruits.

To increase the effectiveness of planning personalized preventive and rehabilitation measures for overweight patients, it is proposed that practical doctors use the algorithm we developed for predicting pathological obesity in children with different genotypes of the lactase gene at an early diagnostic stage. The use of lactase gene genotyping and a HBTLL in all overweight patients is recommended to exclude lactose maldigestion. Children with obesity, with the genotype of the C/C 13910 lactase gene and a HBTLL index less than $19 \mathrm{pmm}$, must be prescribed low-lactose diet therapy with the calculation of the level of lactose tolerance according to the innovative "Low-lactose diet" computer program that we have presented (15). In children with obesity, with the genotype of the C/C 13910 lactase gene and lactose maldigestion with a HBTLL index of more than $20 \mathrm{pmm}$, it is necessary to use a combination of low-lactose diet therapy and exogenous lactase drug at a dose of 3000 ALU three times a day for 1 month (16).

Prevention of insulin-resistant obesity in a child must begin from the moment of birth during the preparation of a genetic passport, especially when there is the hereditary burden of the metabolic syndrome, the pathological course of pregnancy in the mother, macrosomia and the presence of the C/C 13910 genotype of the whole family.

\section{AUTHORS' CONTRIBUTIONS}

AA was responsible for the idea and study design, looked over the articles and extracted the data. AN analyzed the data and interpreted it. Both authors reviewed the paper and approved the final manuscript.

\section{COMPLIANCE WITH ETHICAL STANDARDS}

Conflict of Interest: The authors declare that they have no conflict of interest.

Funding: There is no funding source.

Ethical approval: All procedures performed in studies involving human participants were in accordance with the ethical standards of the institutional and/or national research committee and with the 1964 Helsinki declaration and its later amendments or comparable ethical standards. The submissions were reviewed by the Ethics Committee of the State Institution "Dnipropetrovsk Medical Academy of the Ministry of Health of Ukraine" (meeting minutes No. 2 of February 10, 2016 and minutes from meeting No. 5 of February 7, 2018). Informed consent: Informed consent was obtained from all individual participants included in the study.

\section{REFERENCES}

1. Levitt M, Wilt T, Shaukat A. Clinical implications of lactose malabsorption versus lactose intolerance. J Clin Gastroenterol 2013; 47(6): 471-80.

2. Lobstein T, Jackson-Leach R. Planning for the worst: estimates of obesity and comorbidities in school-age children in 2025. Pediatric Obesity 2016; 11(5): 321-5.

3. Styne DM, Arslanian SA, Connor EL, et al. Pediatric Obesity-Assessment, Treatment, and Prevention: An Endocrine Society Clinical Practice Guideline. J Clin Endocrinol Metab 2017; 102(3): 709-57.

4. Andrade MI, Oliveira JS, Leal VS, et al. Identification of cutoff points for Homeostatic Model Assessment for Insulin Resistance index in adolescents: systematic review. Rev Paul Pediatr. 2016; 4(2): 234-42. (In Portuguese).

5. Misselwitz B, Butter M, Verbeke K, et al. Update on lactose malabsorption and intolerance: pathogenesis, diagnosis and clinical management. Gut 2019; 68(11): 2080-91.

6. Ahrens W, Moreno LA, Marild S, et al. IDEFICS consortium. Metabolic syndrome in young children: definitions and results of the IDEFICS study. Int J Obes (Lond) 2016; 38(2): 4-14.

7. Reinehr T. Metabolic Syndrome in Children and Adolescents: a Critical Approach Considering the Interaction between Pubertal Stage and Insulin Resistance. Curr Diab Rep 2016; 16(1): 8.

8. Chung ST, Onuzuruike AU, Magge SN. Cardiometabolic risk in obese children. Ann NY Acad Sci 2016; 1411: 166-83.

9. Vetter TR. Descriptive Statistics: Reporting the Answers to the 5 Basic Questions of Who, What, Why, When, Where, and a Sixth, So What? Anesth Analg 2017; 125(5): 1797-802.

10. Yang Y, Dong B, Zou Z, et al. Association between Vegetable Consumption and Blood Pressure, Stratified by BMI, among Chinese Adolescents Aged 13-17 Years: A National Cross-Sectional Study. Nutrients 2018, 10(4): E451.

11. Paasela M, Kolho K-L, Vaarala O, Honkanen J. Lactose inhibits regulatory T-cell-mediated suppression of effector T-cell interferon- $\gamma$ and IL-17 production. British Journal of Nutrients 2014; 112(11): 1819-25.

12. Ostrowska L, Witczak K, Adamska E. Effect of nutrition and atherogenic index on the occurrence and intensity of insulin resistance. Pol Arch Med Wewn 2014; 123(6): 289-96.

13. Umer A, Kelley GA, Cottrell LE, et al. Childhood obesity and adult cardiovascular disease risk factors: a systematic review with meta-analysis. BMC Public Health 2017; 17(1): 683.

14. Vega-Carrascal I, Bergin DA, McElvaney OJ. Galectin-9 signaling through TIM-3 is involved in neutrophil-mediated Gram-negative bacterial killing: an effect abrogated within the cystic fibrosis lung. J Immunol 2014; 192 (5): 2418-31.

15. Abaturov AE, Nikulina AA, Logvinov DV, et al. (Dietotherapy in children with obesity associated with adult lactase deficiency). Zdorov'ye Rebenka 2017; 12(6): 657-62. (In Ukrainian).

16. Abaturov A, Stepanov Y, Nikulina A. Treatment of lactase deficiency in children's obesity with genotype C/C 13910 of lactase gene. Wiad Lek 2019; 72(1): 17-21. 